$$
\text { N93-10393 }
$$

\title{
Turbulence Measurements of High Shear Flow Fields in a Turbomachine Seal Configuration
}

\section{by}

\section{Gerald L. Morrison, Professor}

\section{Robert E. DeOtte, Jr., Research Engineer}

H. Davis Thames III, Graduate Student

Mechanical Engineering Department

Turbomachinery Laboratory

Texas A\&M University

College Station, Texas $\mathbf{7 7 8 4 3}$

Presented at

1992 Conference on Advanced Earth-To-Orbit Propulsion Technology

May 19-21, 1992

Huntsville, Alabama 



\title{
Turbulence Measurements of Iligh Shear Flow Fields in a Turbounachine Seal Configuration
}

\author{
G.L. Morrison, R.E. DeOtte. Jr., and H.D. Thames, III' \\ Texas A\&M University \\ Mechanical Engineering Department \\ College Station, Texas $77845-3123$
}

\begin{abstract}
The mean velocity and Reynolds stress tensor throughout a whirling annular seal are presented. The data was collected with a three dimensional laser Doppler velocimeter using phase averaging. Two axial flow conditions $(\operatorname{Re}=12,000$ and 24,000$)$ were studied at one shaft speed $(\mathrm{Ta}=6,600)$. The eccentricity and whirl ratios were $50 \%$ and $100 \%$, respectively. There is a region of high axial momentum at the inlet on the pressure side of the clearance that migrates around the seal to the suction side at the exit. The normalized axial momentum in this region is higher in the low Reynolds number case due to an axial recirculation zone that occurs on the suction side of the rotor at the inlet. The recirculation zone does not accur in the high Reynolds number case. At both Reynolds numbers there is a recirculation zone on the rotor surface in the pressure side of the inlet. This recirculation zone extends from $20^{\circ}$ to $200^{\circ}$ past the rotor zenith in the tangential direction, and is one third of a clearance wide radially. The high Reynolds number recirculation zone is 1.5 mean clearances long, while the low Reynolds number zone extends 2 mean clearances downstream. When compared to previous studies, it is apparent that the tangential momentum is no greater for a seal with whirl than for one without if other parameters are constant. Areas of high tangential momentum occur in the clearance where the axial momentum is low. Average exit plane tangential velocities in the high Reynolds number case are 1.5 times greater than those in the other flow case. These results are in general agreement with predictions made by other investigators.
\end{abstract}

\section{INTRODUCTION}

Annular seals control leakage from high to low pressure areas in pumps, compressors and other turbomachines operating at high speeds. A secondary but equally important purpose is to provide rotordynamic stability (Tam et al., 1988). The seal separates high pressure from low pressure regions, but some leakage is desirable, providing damping for the vibrating system, cooling on the shaft, and increasing stability. Seals with a small axial Reynolds number (generally below 2000) are generally unstable while seals with large axial Reynolds numbers produce large damping and stiffness coefficients and therefore contribute to stability (Allaire et al., 1978).

The mechanical performance of an annular seal is implicilly dependent on the fluid flow through the clearance, since the forces in the seal are generated hydrodynamically. Destabilizing forces tend to move the rotor of an annular seal from its centered position, and whirl usually follows. Whirl occurs when the center of the rotor precesses around the center of the stator. The whirl ratio is defined as $\omega=\omega_{p} / \omega_{1}$. The rotor excitation can become so great that the rotor will contact the stator.

There is usually much effort devoted to characterizing and predicting the damping, stiffness and inertia variables in a seal to decide whether it will be stable prior to production. While the macroscopic effects have been studied extensively, the flow field within the seal has not been investigated because of the difficulty of the measurement. The clearances must be very small to simulate a real machine, and it is very difficult to measure velocities in the wake of the rotor.

Previous Research Annular seals have been investigated since the mid 1970's, when they were identified as contributors to turbomachine instabilities. In 1977 data became available for a wide range of operating conditions because of research directed toward the fuel pumps in the Space Shuttle's main engine (Tam, 1988). The following is a revicw of some relevant research regarding fluid flow through eccentric annular seals. The investigations mainly involved rotordynamic modeling, but one effort was directed wholly to measuring the flow field in an annular seal.

Lessen (1987) performed an analytical study of the flow in a dynamically eccentric whirling annular seal at an arbitrary Taylor number within the Taylor vortex regime. Axial flow through the seal was modeled as plug flow which was justified by assuming high momentum transport from Taylor vortices. Boundary layers near the rotor and stator surface were dominated by Goertler disturbances (instabilities akin to Tollmein-Schlichting waves). Goertler disturbances were induced by the curvature of the boundary surface, and in this geometry are of far less importance than the Taylor vortices (Schlichting, 1979). The width of the Goertler disturbance-dominated

regime was taken to be one unit of the non-dimensional Blasius variable, $y \sqrt{U / v x}$, at which point the local velocity $u / U_{\text {ove }}$ was 0.33 . Lessen suggests that marginally unstable Goertler disturbances will be superseded by Tollmein-Schlichting waves if the sum of squared axial and tangential Reynolds numbers exceeds the critical Reynolds number for their formation: $\operatorname{Re}_{x}{ }^{2}+\operatorname{Re}_{0}{ }^{2} \geq \operatorname{Re}_{a n}{ }^{2}$. This indicates that the nature of the turbulence in the seal resembles flat plate turbulence at high tangential and axial Reynolds numbers. It was further found that the reaction forces in the radial direction were inertial in nature and could induce instabilities, and that the tangential reaction force was purely a function of viscous forces. Finally the ratio of potential core circulation to shaft circulation was the same in the eccentric rotor case as in the concentric. Lessen's important finding was that tangential flow circulation did not change when the rotor was offsct eccentrically (whiri was not considered).

'This work was performed under NAG3-181 with the NASA Lewis Research Center and the Texas A\&M University Turbomachinery Laboratory Research Consortium. 
Chen and Jackson (1984) studied the effect of axial eccentricity (displacement in the $\mathrm{r}-\theta$ plane) and misalignment (angular displacement in the $Z$-r plane) on rotordynamic coefficients in annular seals. They suggested that the forces generated in high pressure seals are greatest in straight annular seals, and developed relationships between reaction forces and leakage rate through the seals that included the effects of eccentricity, misalignment and rotation. A concentric tapered annular seal was used as a model for the eccentric seal. and it was found that the effect of eccentricity or misalignment on the leakage rate was not as great when the flow regime was turbulent. The seal leakage increased with the degree of eccentricity, and decreased with the degree of misalignment.

Allaire et al. (1978) obtained an analytical solution of the semi-empirical bulk flow equations developed by Hirs (1978) for pressure in an eccentric non-rotating annular seal. The seal length-to-diameter ratio was 0.16 and the axial Reynolds number was about an order of magnitude larger than the tangential. He found that in seals with a small axial Reynolds number the pressure drop though the seal was mainly due to friction effects. but as the leakage rate increased the Bernoulli effect became stronger and high pressure gradients existed through the seal. At very high flow rates, large head losses occurred at the entrance to the seal and the pressure distribution throughout the seal tended to be constant. The load-carrying capacity of the seal was small for the low flow rate case, increased as the flow rate increased, peaked where the pressure gradients were high, and then decreased as the flow rate increased.

Hashimoto et al. (1988) investigated short, eccentric journal bearings to find the effect of fluid inertia on trajectory. This was basically an investigation of whether laminar flow theory would suffice in turbulent conditions. The length-to-diameter ratio of the journal was 0.5 . The averaged form of the momentum and continuity equations was used in the analysis and reaction forces were calculated for the fluctuating pressure term. Through numerical simulation the trajectory of the journals was calculated and it was demonstrated that fluid inertial effects help contribute to the stability of the system.

Kanemori and Iwatsubo (1989) considered a long annular seal with a length-to-diameter ratio of 3.0. The eccentricity of the shaft was adjustable and misalignment was not considered. They concluded that for small axial flow rates the results were similar to predictions from Fritz's theory. This did not consider the axial flow and simply suggested that the reaction force in the seal was dependent on the whirl velocity. It was determined that the tangential reaction force was destabilizing for whirl ratios between zero and 1/2. and that the seal was unstable at small $R_{x}$, but stable at higher Reynolds numbers. The amplitude of the tangential reaction force was minimized when the whirl ratio was $1 / 2$.

Simon and Frene (1989) studied convergent and divergent annular seals with a cryogenic working fluid. They considered the compressibility and variable viscosity of the fluid, inlet swirl and pressure drop effects. The initial assumption was that inertial effects of the fluid in the seal could be neglected. A numerical example was run with axial Reynolds numbers about $: 30,000$ and 160,000 . This example indicated the utility of the variation of the fluid properties in the analysis. Their results were in good agreement with experimental data.

Tam et al. (1988) conducted a numerical study of eccentric annular seals without misalignment, using a model of the fluid forces based on the average fluid circumferential velocity ratio. The model was based on the assumption that the dynamic forces were rotating at the precession speed. The numerical grid was three dimensional and rotated with respect to a stationary observer at the precession rate of the rotor, i.e. the rotor was a stationary reference frame. The grid consisted of $12 \times 6 \times 16$ cells in the tangential, radial, and axial directions, and was considered invariant in time since the orbit was circular and periodic. The Prandtl mixing length turbulence model was selected because of its simplicity and because the mixing length was obviously the clearance of the seal. The eddy viscosity concept, $\mu_{1}=\rho l_{\mathrm{m}}^{2} \phi$. was used to simulate the effect of the turbulence levels on the mean velocities. The pressure drops ranged from 0.3 to 18.5 bars, the rotational shaft speeds from 1442 to $5085 \mathrm{rpm}$, the eccentricity ratios from 0.24 to 0.8 , and the whirl ratios from 0.3 to 1.0 . Bromotriflouromethane and oil were modeled as the working fluids.

The results of the study indicated that there were significant changes in the local values of the seal dynamic forces and that large tangential separation zones existed through the seal. The existence of the recirculation zones was found to depend on the shaft and precession speeds, with increasing likelihood at lower shaft speeds and higher precession speeds (whirl ratio approaching 1.0) Recirculation zones were located along the stator wall, beginning just prior to the minimum clearance location, and rotated at the precession speed. Negative preswirl (opposing the direction of seal rotation) intensified the recirculation zones while preswirl in the direction of rotation weakened the secondary flow.

The effects of eccentricity and rotation speed on leakage flow rate were also studied. Leakage was most dependent on rotational speed when the precession speed was low. Increasing precession speed increased the leakage rate through the seal because of a pumping effect.

Fluid injection from four stator positions into the clearance was also studied. It was found that injection in the direction of the shaft rotation increased leakage while injection against the rotation decreased leakage. Injection essentially mimicked the preswirl effects mentioned earlier, but downstream of the inlet.

Johnson (1989) and Morrison et al. (1991) used a three dimensional laser Doppler anemometer to study an annular seal positioned first concentrically and then eccentrically. The eccentricity was created by moving the stator closer to the rotor at an angular position of interest (the rotor was not whirling). Johnson measured axial-radial profiles at $\theta=0^{\circ}, 90^{\circ}, 180^{\circ}$, and $270^{\circ}$. The leakage flow was $4.86 \mathrm{l} / \mathrm{s}(77 \mathrm{gpm}, \mathrm{Re}=24,000)$ and the rotational speed varied from 0 to $3600 \mathrm{rpm}(\mathrm{Ta}=0$ to 6,600$)$. The preswirl was $0^{\circ},-45^{\circ}$, and
$+45^{\circ}$.

For the rotor concentric with the stator, tangential velocities were higher $\left(\sim 0.3 \mathrm{~W}_{\text {sh }}\right)$ for positive preswirl than for no preswirl $\left(\approx 0.18 \mathrm{~W}_{\mathrm{sh}}\right)$ or negative preswirl $\left(-0.25 \mathrm{~W}_{\mathrm{at}}\right.$ at the inlet and $0.10 \mathrm{~W}_{\mathrm{bb}}$ at the exit). For the eccentrically mounted stator, tangential velocities vary to satisfy continuity considerations being greater in the small clearance than in the large. In the large clearance the tangential velocily did not increase along the length of the seal but in the small clearance there was azimuthal acceleration. The effect of preswirl was similar to that for the concentric geometry.

In summary, previous studies showed that eccentrically aligned rotors affect annular seals in several ways. The core circulation in an eccentric seal is the same as in concentric seals (Lessen, 1987). Whirling rotors increase the leakage flow rate through seals. presumably due to a pumping effect (Chen and Jackson, 1984 and Tam, 1988). High leakage rates through the seal decrease the axial pressure gradient across the rotor because of high head losses in the entrance region (Allaire, 1978). High turbulence levels enhance the stability of whirling journals. suggesting that once whirling begins it may be damped out (Hashimoto et al., 1988). Seals are unstable at 
low axial Reynolds numbers (below 2000) (Allaire et al. 1978 and Kanemori and Iwatsubo, 1989). Reaction forces are destabilizing when the whirl ratio is less than 0.5 (Kanemori and Iwatsubo, 1989). Tangential recirculation zones discovered in whirling seals during certain operating conditions were seen to diminish if there was preswirl or fluid injection in the direction of rotor rotation, and were enhanced if preswirl or injection opposed the rotor circulation direction (Tam, 1988). Morrison, et al. (1991) and Johnson (1989) showed that preswirl effects tangential velocity development in concentric and statically eccentric seals.

Measuring the velocity profile in the whirling seal is the only means to test the validity of assumptions used in the analysis of other researchers. For example, it is highly unlikely that the axial velocity distribution in the seal can be modeled as a plug flow as hypothesized by Lessen. Theories that were proposed in these studies and tested include the proposition that 1) the tangential velocity distribution does not increase in the presence of whirl, 2) there is a tangential velocity recirculation zone along the stator, and 3) that seal leakage increases with eccentricity.

\section{PROGRAM OBJECTIVES}

To address the lack of experimental data, the mean velocity profile and turbulence leveis in an annular seal (37.3 $\mathrm{mm}$ long, $164.1 \mathrm{~mm}$ diameter, and a nominal clearance of $1.27 \mathrm{~mm}$ ) were measured for evaluation of flow phenomena. Figure 1 illustrates the test section in which water is the working fluid. The stator contains an optical window through which the beams of a three-dimensional laser Doppler velocimeter are directed. An eccentricity ratio of 0.5 is imposed on the rotor by mounting it on an eccentric bushing, which is attached to the shaft of an electric motor (the eccentricity ratio is defined as the ratio of the off-centeredness of the rotor to the clearance width, $\epsilon=\mathrm{e} / \mathrm{c}$ ). A detailed description of the facility and error analysis are contained in Johnson (1989) and Morrison, et al.(1991). In real machines eccentricities can be attributed to misalignment during assembly, side loads such as rotor weight, impeller loads (Nelson and Nguyen, 1988), or destabilizing seal forces. Instabilities caused by pressure fluctuations in the flow can also induce eccentric whirling.

By varying the flow rate through the seals, Reynolds numbers and Taylor numbers typical of full scale applications were obtained. The seal angular speed was $3600 \mathrm{rpm}$ for all the tests. The leakage flow rates were $2.43 \mathrm{l} / \mathrm{s}(38.5 \mathrm{gpm})$ and $4.86 \mathrm{l} / \mathrm{s}$ ( $77 \mathrm{gpm}$ ), with an eccentricity ratio of $50 \%$. Since the rotor was connected directly to the shaft of the motor, the whirl ratio was $100 \%$. The Reynolds numbers investigated were $12,000\left(U_{\mathrm{mm}}=3.7 \mathrm{~m} / \mathrm{s}\right)$ for the first flow case and $24,000\left(\mathrm{U}_{\mathrm{am}}=7.4 \mathrm{~m} / \mathrm{s}\right)$ for the second, while the Taylor number for both cases was $6,600\left(\mathrm{~W}_{\mathrm{th}}=28.7 \mathrm{~m} / \mathrm{s}\right)$.

\section{RESULTS}

The rotor is spinning clockwise and whirling in the same direction as it is rotating. Angles are measured from the minimum clearance point in a clockwise direction, and the minimum clearance point is the rotor's zenith. The suction side of the clearance is on the left of the rotor, and the pressure side is on the right.

\section{$\operatorname{Re}=12.000$}

Mean Velocities Significant features of the mean velocity profiles are that the axial velocity peaks on the pressure side of the clearance at the seal entrance and rotates around the seal circumferentially until it is on the suction side at the exit. The radial velocity distribution generally points outward to the stator at the seal inlet, and dissipates downstream. An axial vena contracta exists over the first two clearances on the pressure side of the rotor.

Figures 2 and 3 present contours for the three mean velocity components and the axial velocity variance. Figure 2 represents the flow at five axial locations along the entire length of the seal while Figure 3 presents data from -0.02 to $0.14 \mathrm{ZL}$ of the flow. Upstream of the inlet (Figure 3 ) the now is very sensitive to the motion of the rotor, as indicated by the large radial velocities away from the rotor where it accelerates toward the stator. On the pressure side of the seal there are large tangential velocities and very small radial velocities. The large radial velocity zone is explained partially by the flow in the plenum upstream of the seal moving with the rotor from top to bottom. The rotor is pulling the flow along with it for angles larger than $180^{\circ}$ and pushing flow away from it for angles less than $180^{\circ}$. Once the flow enters the seal clearance, the high radial velocities at $90^{\circ}$ diminish and the flow follows the movements of the rotor more closely. At the inlet the $\partial / \partial \theta$ gradients are most apparent. No tangential recirculation zones were seen along the stator in this flow case; therefore, if one exists it must be between the stator and the first radial grid line.

Upstream of the inlet to the seal, at $Z / L=-0.02$ (Figure 3 ), the maximum axial velocity $\left(1.3 \mathrm{U}_{\mathrm{we}}\right.$ where $\left.\mathrm{U}_{\mathrm{sw}}=3.7 \mathrm{~m} / \mathrm{s}\right)$ occurs $+95^{\circ}$ from the rotor zenith $\left(\theta=0^{\circ}\right.$ position). There is a negative zone of axial velocity on the other side of the seal which reaches $-0.4 U_{\text {ave }}(1.5$ $\mathrm{m} / \mathrm{s}$ ). It is evident that at this location the rotor is affecting even the flow upstream of the seal. The radial flow component is moving very quickly away from the rotor $\left(0.9 \mathrm{U}_{\text {ave }}-3.3 \mathrm{~m} / \mathrm{s}\right)$ from about $\theta=90^{\circ}$ to $180^{\circ}$, but is depressed everywhere else. This is representative of the motion of the rotor, which is pulling fluid toward it in the lower half of the stator, and pushing it away on the other side. The tangential flow component is uniformly distributed around the clearance at $0.12 \mathrm{~W}_{\mathrm{b}}$ ( $\mathrm{W}_{\mathrm{w}}$ is the rotor surface velocity, $28.7 \mathrm{~m} / \mathrm{s}$ ), which is on the order of $U$. The inlet preswirl is caused by the rotation of the rotor which influences the upstream velocities through the large volume of water trapped in the hollow section of the rotor. The tangential velocity is accelerated into the minimum clearance area beginning at $260^{\circ}$. To satisfy continuity, the axial or radial velocities must be reduced. Consequently, the negative axial zone begins at $260^{\circ}$ also, but the radial velocities do not seem to react.

At the entrance, $Z \Omega=0$ (Figures 2 and 3 ), the maximum axial velocity increases to $2.4 \mathrm{U}_{\text {sve }}(8.9 \mathrm{~m} / \mathrm{s}$ ) and the peak location moves to $70^{\circ}$. The size of the back flow area diminishes, but it does not move relative to its previous position. It appears that the peak axial velocity is located in a region of decelerating tangential flow. For equal axial pressure drop across the seal at all azimuthal angles, the greatest axial velocity should be in the largest clearance area if there is no rotation or whirl. But, the tangential component accelerates toward the minimum clearance area, so the axial momentum decreases to satisfy continuity. The smallest tangential velocities 
$\propto c c u r$ in a band from $60^{\circ} 10230^{\circ}$, where the largest axial velocities are located. The greatest radial velocities continue to occur between $90^{\circ}$ and $180^{\circ}$, and the maximum radial velocity is still $0.9 \mathrm{U}_{\text {uve }}(3.3 \mathrm{~m} / \mathrm{s})$ outward.

The axial velocity component accelerates down the seal, and the peak begins to rotate further away from the rotor zenith at $\mathrm{Z} / \mathrm{L}=0.04$ (Figure 3). The maximum axial velocity reaches $2.6 \mathrm{U}_{\text {swe }}(9.6 \mathrm{~m} / \mathrm{s})$ and rotates to $90^{\circ}$ as the tangential momentum transports the large axial momentum zone around the seal. At the same time, an axial recirculation zone (due to the vena contracta effect at the seal entrance) extends around the rotor, from $80^{\circ}$ to $320^{\circ}$ on the rotor surface. The shear layer between the positive and negative axial velocities develops intensely at $130^{\circ}$, and the large axial velocities progress outward from the rotor toward the stator side of the clearance. The tangential velocities begin to increase also, especially on the suction side of the seal, where there is little axial momentum. The radial velocities clearly define the vena contracta region on the pressure side of the clearance, a strong counter flow exists at the rotor surface $\left(\approx 350^{\circ}\right.$ to $180^{\circ}$ ) with a positive radial velocity further into the clearance. The large positive radial velocity zone has moved around the seal slightly to $300^{\circ}$. There are large $\partial \mathrm{V} / \partial \mathrm{r}$ gradients in the shear layer region around the axial recirculation zone and through the vena contracta shear layers. 13

Farther down the seal, at $Z /=0.07$ (Figure 3 ), the $U$ component begins to drop in magnitude, with a peak velocity of $2.1 U_{\text {sue }}$ $(7.8 \mathrm{~m} / \mathrm{s})$ at $\theta=80^{\circ}$. The recirculation at $180^{\circ}$ on the boltom of the rotor decreases in magnitude, and the recirculation on the opposite side of the rotor from the maximum velocity region subsides as well. The large $U$ zone begins to spread out around the seal, and is located out closer to the stator than the rotor. Large $\bar{u}^{\prime} u^{\prime}$ stresses along the rotor surface divert the flow out to the stator. The radial velocities are directed into the rotor in much of the zone occupied by the high axial velocities, but are positive in the $U$ recirculation areas. The $W$ distribution is more uniform, at $0.20 \mathrm{~W}_{\mathrm{A}}(5.7 \mathrm{~m} / \mathrm{s})$ throughout much of the seal. The tangential velocity contours are closer together in the small clearance area of the seal. but they are still evenly distributed throughout the clearance. It appears that the $\partial W / \partial r$ gradients scale with the clearance width.

Between $Z /=0.07$ and 0.21 the peak axial velocity decreases and spreads over a much greater area of the clearance as the flow continues downstream. The deceleration is due to shear along the stator wall and conservation of momentum, since the high axial flow area is spread out over more of the seal. This is the region where the vena contracta diverges out to reattach to the rotor surface, and the axial recirculation disappears. The steep $\partial \mathrm{V} / \partial \mathrm{r}$ gradients toward the rotor have also diminished at this point. The positive and negative radial velocity zones begin to equalize on either side of the seal and approach zero.

At the midplane of the seal $(Z / L=0.50$, Figure 2$)$ the $U$ profile becomes aimost uniformly distributed, with a peak of $1.1 U_{\text {wwe }}$ $(4 \mathrm{~m} / \mathrm{s})$ at $\theta=135^{\circ}$. The $0.8 \mathrm{U}_{\text {ave }}(3 \mathrm{~m} / \mathrm{s})$ contour extends throughout most of the circumference of the seal. The radial velocities are virtually zero throughout the entire seal, and the tangential velocities remain very uniformly distributed at an average of $0.20 \mathrm{~W}$ th $(5.7 \mathrm{~m} / \mathrm{s})$.

Down the seal at $Z L=0.77$ a radical shift in the axial velocities occurs. The peak velocity increases to $1.5 \mathrm{U}_{\text {mut }}(5.5 \mathrm{~m} / \mathrm{s})$ and rotates around $10 \theta=295^{\circ}$. The axial recirculation does not reappear, and the peak velocity is fairly close to the rotor, indicating that there are low turbulence levels there. The positive and negative radial velocity zones have also rotated to opposite sides of the seal, with the negative areas following the peak axial velocity zone. The magnitude of the radial velocities is below $0.05 U_{\text {ave }}(0.18 \mathrm{~m} / \mathrm{s})$. The tangential profile shifts with the larger tangential velocities located in the pressure side of the seal, which is consistent with the downstream trend that large tangential velocities belie small axial velocitics, and vice versa.

The axial velocity profile continues to change all the way to the exit plane $(Z / L=1.00)$ with the peak axial velocity progressing toward the rotor zenith. The radial velocities are similar at $Z / L=0.77$ and 1.00 . At the exit, tangential velocities reach a maximum across the width of the clearance with high tangential velocities extending from the pressure side of the seal at $\theta=60^{\circ}$ to the suction side at $\theta=200^{\circ}$ at values near $0.3 \mathrm{~W}_{\mathrm{sh}}\left(8.6 \mathrm{~m} / \mathrm{s}\right.$ or $\left.2.3 \mathrm{U}_{\mathrm{ve}}\right)$.

Turbulence hevels Upstream of the inlet to the seal the " $"$ Reynolds stress is evenly distributed throughout the clearance averaging $0.1 \mathrm{U}_{\text {we }}=$ (Figure $3,1.4 \mathrm{~m}^{2} / \mathrm{s}^{2}$ ). This stress level is what remains of the grid turbulence generated at the entrance to the plenum. At the inlet. the normal stresses begin building up, thereby inhibiting the flow along the rotor. The $\|^{\prime}$ 'stress increases sharply along the rotor from $45^{\circ}$ to $175^{\circ}$, and the $\delta u^{\prime} " 7 \partial \mathrm{r}$ gradients are very large halfway into the clearance. This normal stress, which is analogous to a pressurc (Rodi. 1984), retards the axial flow along the rotor. Similarly, gradients of the normal stress are considered as dynamic pressure gradients (Tennekes and Lumley, 1990). The high "pressure" area blocks axial flow along the rotor, diverts it up into the vena contracta, and induces recirculation behind it. Downstream of the inlet at $Z L=0.04$ (Figure 3), the $\bar{u}^{\top}$ stresses reach a maximum of $0.9 U^{2}(12$ $\left.\mathrm{m}^{2} / \mathrm{s}^{3}\right)$ at $70^{\circ}$. The peak is located a quarter clearance from the rotor, begins developing at $310^{\circ}$, builds to a maximum at $70^{\circ}$, then diminishes to a minimum at $300^{\circ}$. The $\partial \overrightarrow{u^{\prime}} \boldsymbol{\|} \mathrm{J} \partial \mathrm{r}$ gradients between the $\overline{u^{\prime}}$ peak and the $U$ peak are very steep in the shear layers along the recirculation zone. Three quarters of the clearance from the rotor and at $80^{\circ}$ the $\overline{u^{\prime} u^{\prime}}$ stresses recede to $0.2 U_{\text {ave }}{ }^{2}$, and the $U$ velocity reaches a maximum. This location is where the vena contracta reaches its narrowest width. The $\partial \bar{u} u^{\prime} 7 \partial \theta$ gradients are greater on the upstream side of the peak and then trail off at a gentler slope downstream. At $Z / L=0.07$ the $\bar{u}^{\prime} u^{\prime}$ stress is convected tangentially around the seal $1080^{\circ}$ from $70^{\circ}$ just upstream. The structure is still intact but the gradients are smaller than before. The peak is still dropping, reaching $0.7 U^{2}\left(9.5 \mathrm{~m}^{2} / \mathrm{s}^{2}\right)$ at $80^{\circ}$. The $\bar{u}^{\prime} u^{\prime}$ stresses dissipate rapidly between $\mathrm{Z} /=0.07$ and $\mathrm{Z} /=0.21$. The peak level convected to $100^{\circ}$, so the convection of the $\overline{\|} \|^{\prime}$ stress increases also. The $\overline{\|}$ gradients in both the axial and tangential directions decrease in magnitude. At $\mathrm{Z} /=0.21$ the " $"$ normal stress is distributed across the entire clearance on the pressure side of the rotor. This reduces the mean velocity peak, whereas before the high " $"$ ' levels on the rotor surface had pushed the high $U$ velocities toward

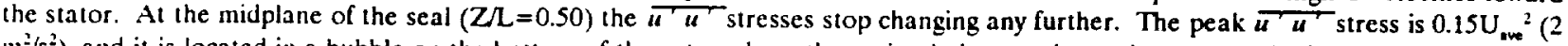
$\left.\mathrm{m}^{2} / \mathrm{s}^{2}\right)$, and it is located in a bubble on the bottom of the rotor where the recirculation was located nearer to the inlet. Another bubble develops in the minimum clearance area. For the rest of the seal these structures change little, suggesting that production and dissipation are in equilibrium from this point on.

\section{$\underline{\operatorname{Re}=24.000}$}

Mean Velocities The mean velocity contour plots reveal an interesting change in the upstream flow patterns with the increased flow rate through the seal. Upstream and at the inlet to the seal (Figures 4 and 5) the flow vectors on the pressure side are pointing inward, as 
opposed to outward as they did in the slower flow rate.

Upstream of the seal at $Z / L=-0.02$ (Figure 5), the mean axial velocity profite reaches a peak of greater than $0.9 \mathrm{U}_{\text {ave }}\left(6.6 \mathrm{~m} / \mathrm{s}\right.$, where $\left.U_{\text {ave }}=7.4 \mathrm{~m} / \mathrm{s}\right)$ between $60^{\circ}$ and $135^{\circ}$. There is no backflow out of the seal as in the lower Reynolds number case because the upstream pressure is higher, and the pressure developed in the seal cannot overcome it. The radial velocities are generally pointed inward toward the seal as the flow has just been diverted inward by the curve in the plenum wall. The greatest inward mean radial velocities are located in the same region as the high U's. There is much less significant preswirl at the inlet for this case. The inlet $\mathrm{W}$ does not exceed $0.08 \mathrm{~W}_{\mathrm{sh}}\left(0.33 \mathrm{U}_{\text {sve }}, 2.4 \mathrm{~m} / \mathrm{s}\right)$ over most of the clearance.

At the seal inlet (Figure 4) the axial flow component begins accelerating into the seal. The peak axial velocity is $1.5 \mathrm{U}_{\text {ave }}(11$ $\mathrm{m} / \mathrm{s})$ across a band from $30^{\circ}$ to $60^{\circ}$ and stays above $0.5 \mathrm{U}_{\mathrm{zve}}(3.7 \mathrm{~m} / \mathrm{s})$ across the entire circumference of the seal. The $\mathrm{V}$ profiles continue the strong inward trend. The maximum inward velocity reaches $-0.8 \mathrm{U}_{\text {ave }}(-6 \mathrm{~m} / \mathrm{s})$ from $45^{\circ}$ to $190^{\circ}$. It appears that the inward momentum imparted to the flow by the curved stator wall is still affecting the fluid, but at the same time the inlet shape of the seal is directing flow to the cavity under the seal. The tangential velocities begin to increase, with the $0.08 \mathrm{~W},(2.4 \mathrm{~m} / \mathrm{s})$ contour extending almost to the stator from $280^{\circ}$ to $60^{\circ}$, and moving outward through the suction portion of the clearance.

Just downstream of the inlet at $\mathrm{Z} \Omega=0.04$ (Figure 5) the axial velocities are much greater, with a maximum of $2.2 \mathrm{U}_{\text {ave }}(16.3 \mathrm{~m} / \mathrm{s}$ ) occurring at $95^{\circ}$. This peak is very close to the stator, and there are very high $\partial \mathrm{U} / \partial \mathrm{r}$ gradients on either side of the peak. A shear layer exists from $90^{\circ}$ to $180^{\circ}$ and stretches away from the rotor on the maximum clearance side. A mild recirculation zone exists between the rotor and the shear layer with a maximum backflow velocity of $0.1 \mathrm{U}_{\text {ave }}(-0.7 \mathrm{~m} / \mathrm{s})$. This recirculation zone occupies less than $15 \%$ of the clearance and is not visible on the figures. Reattachment of the axial velocity occurs at $180^{\circ}$ where the axial velocities are significantly smaller than on the other side of the clearance. The axial recirculation produces a small vena contracta similar to that for the low Reynolds number case but much smaller in magnitude. The $\mathrm{V}$ profile changes significantly at this point, as the direction of the velocities is redirected back out toward the stator. A maximum of $0.18 \mathrm{U}_{\mathrm{zve}}(1.3 \mathrm{~m} / \mathrm{s})$ at $45^{\circ}$ is surrounded by mild $\partial \mathrm{V} / \partial \mathrm{r}$ gradients on either side. The radial velocities are pointed outward near the rotor and inward near the stator on the wide clearance side of the rotor, indicating the presence of a vena contracta around $135^{\circ}$. Because the axial momentum in this area is so small, the tangential velocities are able to develop quickly, especially in the recirculation zone where $W=0.24 \mathrm{~W}_{\mathrm{sh}}\left(6.9 \mathrm{~m} / \mathrm{s}, 0.9 \mathrm{U}_{\mathrm{sve}}\right)$ in the middle of the clearance from $60^{\circ}$ to $280^{\circ}$.

From $Z / L=0.04$ to $Z / L=0.07$ (Figure 5 ) the axial velocities decrease, only reaching a maximum of $1.9 \mathrm{U}_{\text {sue }}(14 \mathrm{~m} / \mathrm{s})$ at $\theta=120^{\circ}$. The high velocity area is still along the stator, and the steep ju/or gradients near the rotor surface are relaxing. The recirculation zone has disappeared along the rotor, but the velocities are still very low there. The disappearance of the shear layer implies that the axial streamlines are reattached to the rotor. The radial velocities are directed back out toward the stator after turning at the reattachment point. The tangential velocity development diminished with the reattachment of the axial velocity streamlines.

Moving to $\mathrm{Z} /=0.14$ (Figure 5), the $\mathrm{U}$ prolile is more evenly distributed throughout more of the seal, as the peak axial momentum region reaches wider clearances, which is decelerating the flow. The peak axial velocity is $1.5 \mathrm{U}_{\text {ave }}(11 \mathrm{~m} / \mathrm{s})$ and it is located at $90^{\circ}$. The rest of the profile remains attached to the rotor and stator with very mild $\partial \mathrm{U} / \partial \mathrm{r}$ gradients. The axial velocity on the suction side of the rotor is steadily increasing, with the minimum continuous contour at $0.7 \mathrm{U}_{\text {wve, }}$ where just upstream it is $0.6 \mathrm{U}_{\text {sve }}$ The radial velocities continue to decrease in magnitude and now are fairly insignificant. The decrease in axial momentum is acting favorably for the tangential velocities. which are now increasing over the entire seal. The $0.08 \mathrm{~W}_{\mathrm{th}}(2.4 \mathrm{~m} / \mathrm{s})$ level is now extending much further into the maximum clearance region, and it is distributed more uniformly.

From $\mathrm{Z} /=0.14$ to $\mathrm{Z} /=0.50$ (Figure 4 ) the trends discussed above continue: the axial velocity continues to spread more uniformly across the entire seal, the radial velocitics remain small, and the tangential velocities increase with the decrease in axial momentum. At the midplane the axial profile is almost uniform. with regions in the maximum clearance region having velocities which are a little higher. As the location of the maximum axial velocity rotates around the seal. the negative radial velocity zone also moves. By the midplane it is relocated to the minimum clearance region. The tangential velocity develops to $0.08 \mathrm{~W}_{\mathrm{b}}$ all the way out to the stator, and it is increasing in the pressure section of the clearance. reaching $0.16 \mathrm{~W}_{\mathrm{sh}}(4.8 \mathrm{~m} / \mathrm{s})$ by the midplane.

Farther down the seal at $Z \Omega=0.77$ the location of the muximum axial velocity is convected around the seal by the increasing tangential velocity component. The peak axial velocity is at $240^{\circ}$ and has increased to $1.4 \mathrm{U}_{\text {ave }}(10.4 \mathrm{~m} / \mathrm{s})$ as the tangential component is forcing the fluid into a smailer region. The radial velocity is similar to that upstream. with positive values pointing out from the rotor and negative in from the stator. The tangential profile develops significanly, with the $0.24 \mathrm{~W}_{\mathrm{sb}}(6.9 \mathrm{~m} / \mathrm{s})$ zone extending almost entirely across the pressure zone around $60^{\circ}$. This significant increase in the tangential momentum is the mechanism driving the axial velocity peak around to the other side of the clearance.

The axial velocities on the suction side of the cicarance continue to increase as the flow progresses downstream while the tangential velocities increase on the pressure side. This continues to the cxit plane where the peak axial velocity reaches $1.7 \mathrm{U}_{\text {sve }}(12.6$ $\mathrm{m} / \mathrm{s}$ ) at $265^{\circ}$. At the exit plane nearly the whole pressure side of the clcarance is dominated by tangential velocities of at least $0.24 W_{\text {sh }}$ $(0.93 \mathrm{U})$ and on the suction side they are $0.16 \mathrm{~W}_{\mathrm{tb}}(4.6 \mathrm{~m} / \mathrm{s})$. The radial profile remains virtually unchanged through the rest of the seal, not exceeding $0.08 \mathrm{U}_{\text {ave }}(0.6 \mathrm{~m} / \mathrm{s})$. The radial velocities are pointed inward along the stator.

Turbulence levels Upstream of the inlet, in the plenum at $Z \mathrm{~L}=-0.02$ (Figure 5), the normal Reynolds stress term is extremely subdued. which is reflected in the mild gradients in the mean velocily lerms. The " the inlet (Figure 4) the front edge of the rotor causcs changes. The $1 "$ " surface on the bottom side where the recirculation zone is located a bit farther downstream. (Note: the recirculation is evident in the numerical data but does not appear in the contour plots.). This stress decelerates the axial velocity at the surface of the rotor. By

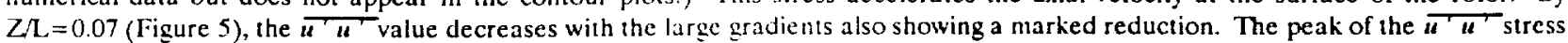
is transported to $110^{\circ}$ by the tangential momentum, and the peak has diminished. Dissipation dominates the flow at this point, where upstream turbulence production is the major mechanism. and works to distribute the turbulence term fairly evenly by midplane. The profile remains reasonably uniform on the suction side, but by the exit plane. $Z /=1.00$, there are again high values of $\overline{u^{\prime}} u^{\prime}$. Although the gradients are steep, it seems likely that the phenomenon is real because of the circumference over which it is distributed. The turbulence producing source at this plane is the step at the end of the seal. 


\section{SUMMARY}

The flow field inside an annular seal whirling at a whirl ratio of 1 and an eccentricity ratio of 0.50 has been measured using a 3-D laser Doppler anemometer system. Reynolds numbers of 12,000 and 24,000 were investigated while the Taylor number was held constant at 6,600 . The flow structure, as evidenced by the velocity and turbulence distributions in the whirling annular seal proved to be far different than in a statically eccentric seal otherwise operating at the same conditions. Prominent features included a peak axial velocity that began in the pressure section of the clearance at the inlet and rotated around to the suction side of the clearance at the exit, a vena contracta on the pressure side of the rotor, and no significant increase in tangential velocity with whirling rotor motion when compared to statically eccentric seals.

The axial flow profiles for both the high and low Reynolds number cases have similarities but also display substantial differences. In both the profiles, the peak axial velocity rotates from the pressure to the suction side of the clearance. In the low Reynolds number case, this started at $60^{\circ}$ with a magnitude of $2.4 U_{\text {sue }}$ over the inlet. By midplane the profile spreads uniformly across most of the clearance. This rotates around the clearance, and at $\mathrm{ZL}=0.77$ the peak reaches the final circumferential position of $300^{\circ}$. Downstream of this position, the peak continues to grow, increasing to $1.9 \mathrm{U}_{\text {sve }}$ at the exit of the seal.

The mean velocity field reveals a highly three dimensional flow with large radial velocities near the inlet of the seal. The normalized axial momentum near the inlet on the pressure side of the rotor is higher in the low Reynolds number case due to an axial recirculation zone that occurs on the suction side of the rotor at the inlet. Another recirculation zone exists on the rotor surface on the pressure side of the inlet at both Reynolds numbers. This recirculation zone extends from $20^{\circ}$ to $200^{\circ}$ in the tangential direction, and is one third of a clearance wide radially (not apparent in the contour plots). The high Reynolds number recirculation zone is 1.5 mean clearances long, while the low Reynolds number zone extends 2 mean clearances downstream. When compared to previous non-whirling flow studies (Johnson (1989)) at similar flow parameters, the tangential momentum does not significantly increase with the onset of whirl. Areas of high tangential momentum occur in regions of the clearance where the axial momentum is low. Average exit plane tangential velocities in the low Reynolds number case are 1.5 times greater than those in the high Reynolds number case.

\section{NOMENCLATURE}

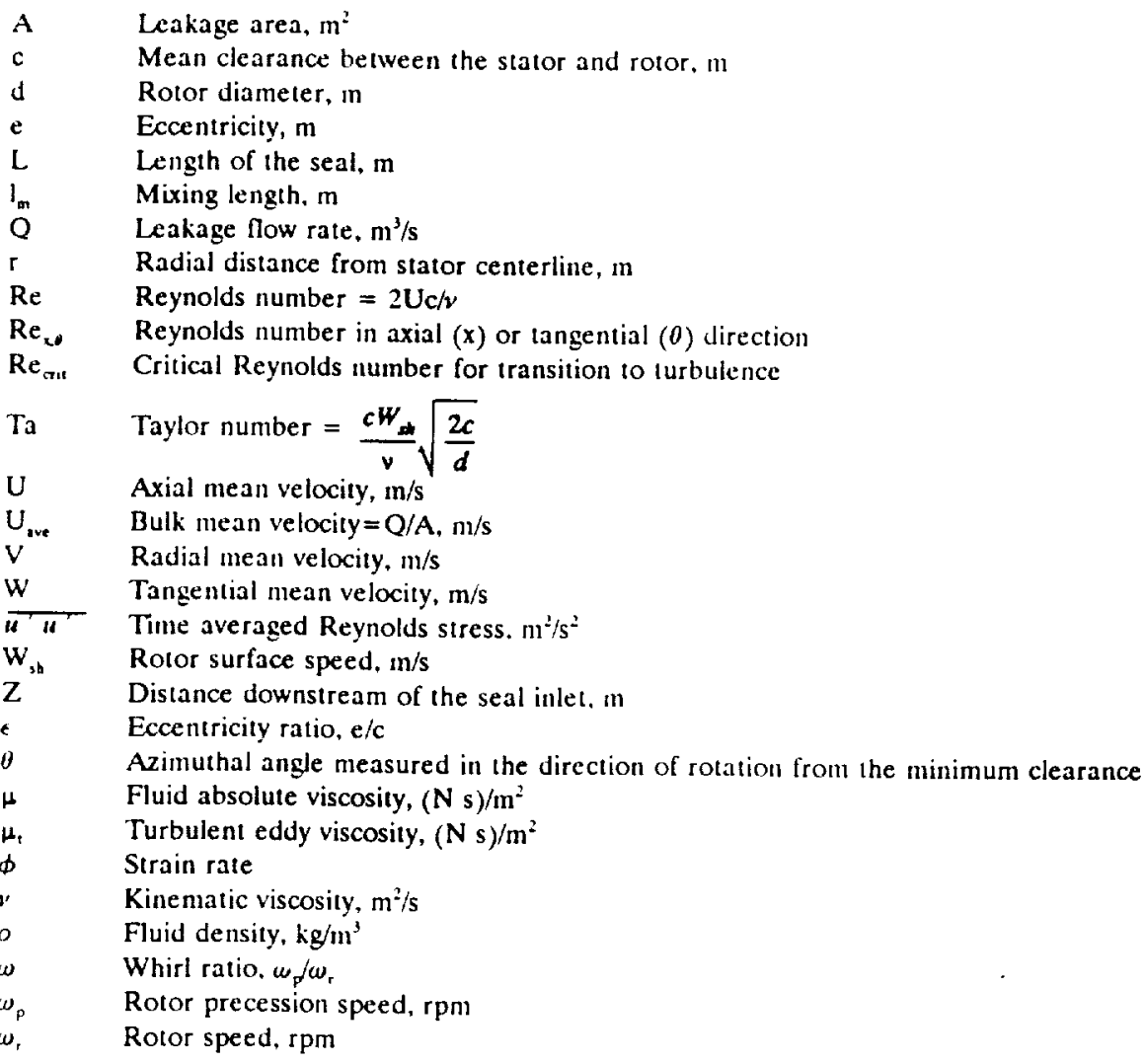

\section{BIBLIOGRAPIIY}

Allaire, P.E.. Lee, C.C., Gunter. E.J, 1978, "Dynamics of Short Eccentric Plain Seals with High Axial Reynolds Numbers," Journal of Spacecraft and Rockets, Vol. 15, pp. 341-347.

Chen. W. C., and Jackson. E.D., 1984, "Eccentricity and Misalignment Effects on the Performance of High-Pressure Annular Seals." ASLE Transactions, Vol. 28, pp. 104-110. 
M., 1988. "Effects of Fluid Inertia Forces on the Dynamic Behavior of Short Journal in Superlaminar Flow Regimes." Joumal of Tribology, Vol. 110, pp. 539-547.

fror Turbulence in Lubricant Films," ASME Journal of Lubricant Technology, Vol. 95 , pp. 137-146.

Johnson, M.C., 1989, "Development of a 3-D Laser Doppler Anemometry System:

Labyrinth Seals," Ph.D. Dissertation, Texas A\&M University, College Staton, Texas, Kanemori, Y., and Iwatsubo, T., 1989, "Exy

International Journal Series II, Vol. 32, pp. 218-224.

Lessen, M., 1987, "Turbulent Flow in Shaft Seas anderements in an Morrison, G.L., Johnson, M.C., and Tatterson, G.B.,

Annular Seal." ASME Journal of Tribology, Vol. 113, pp. 421-427. Nelson, C.C., Nguyen, D.T., 1988, "Analysis of Eccentric Annular Incompress, Vol. 110, pp. 354-360.

Fourier Transforms for Determining Hydrodynamic Force," ASME Journal of Thics - A State of the Art Review, 2nd Edition, International Rodi, W., 1984, Turbulence Models and The Netherlands.

Association for Hydraulic Research, Rotterdam, The Netherill Classic Textbook Reissue, New York.

Schlichting, H., 1979, Boundary-Laver Theory. Mc Characteristics of Turbulent Annular Eccentric Seals: Effect of ConvergentSimon, F., Frene, J., 1989, "Static and Dynamic Character of Tribology, Vol. 111, pp. 378-385.

(1988, "Numerical and Analytical Study

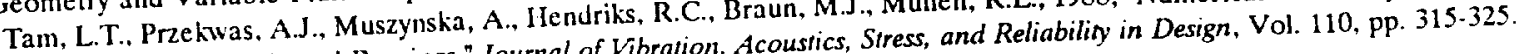
of Fluid Dynamic Forces in Seals and Bearings," Journal of Vibration, Acousits,

\section{Texas A\&M Seal Rig Composite Drawing}

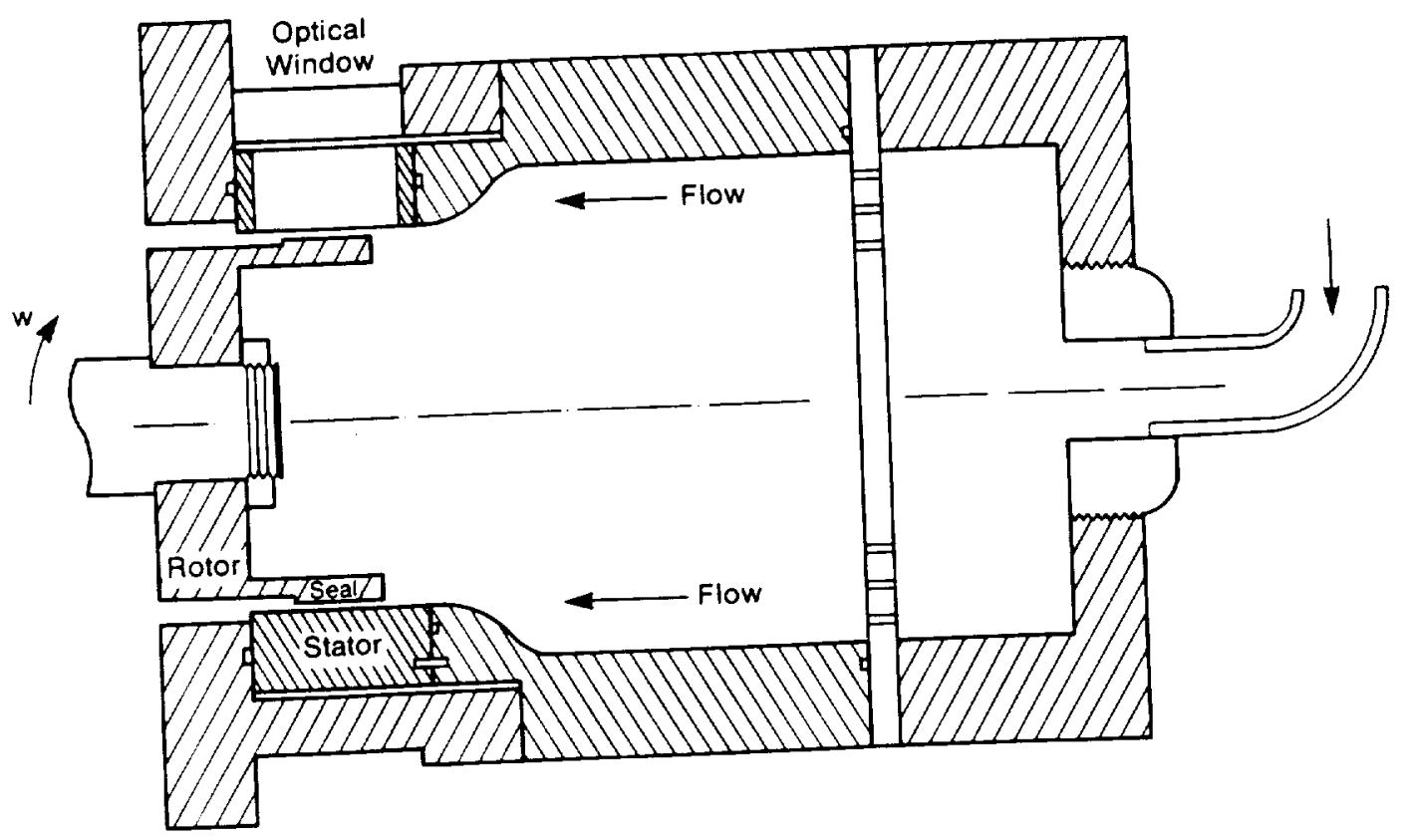

Figure 1. Annular seal test facility. 


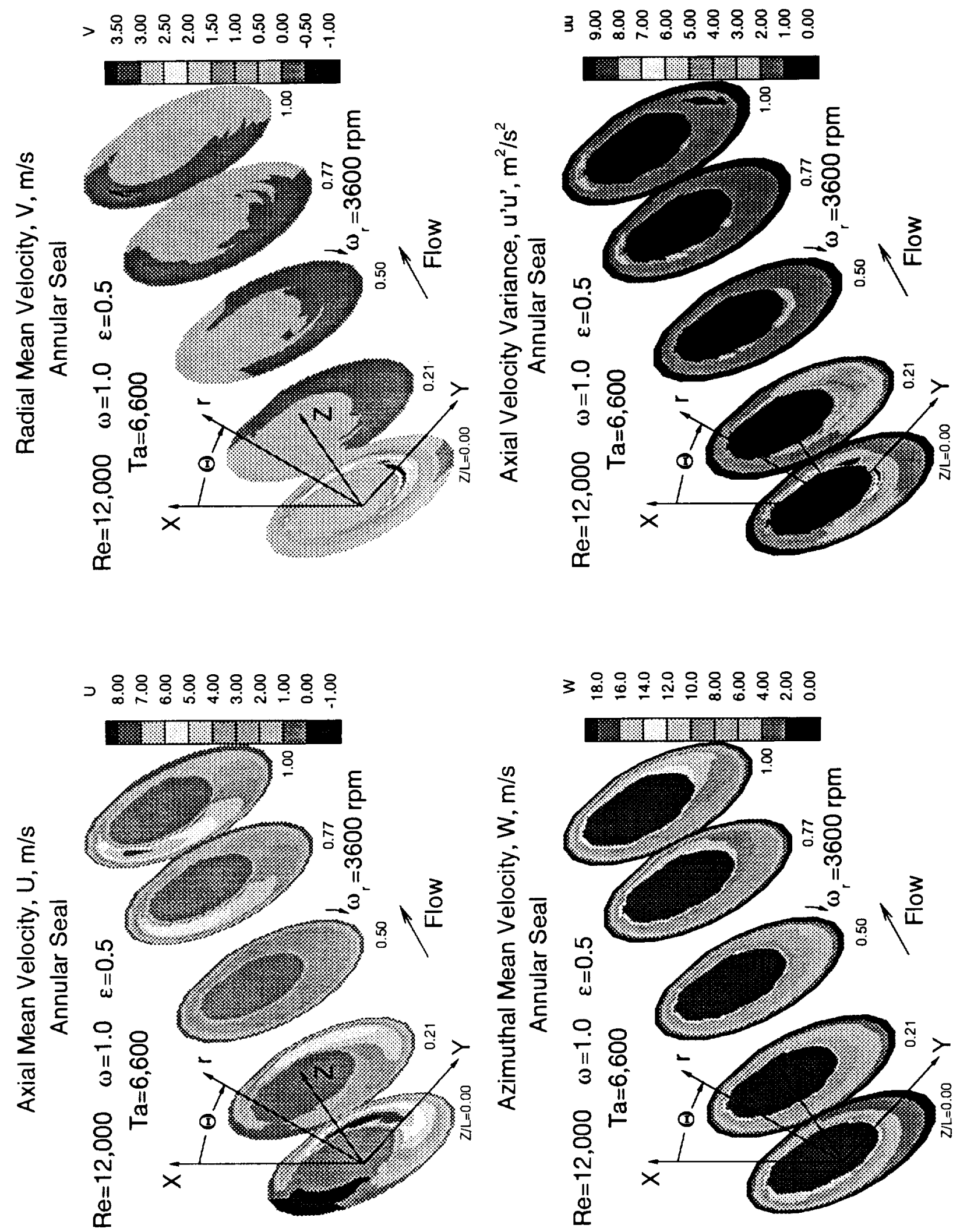

Figure 2. Mean velocity and axial velocity variance, $\operatorname{Re}=12,000,0.00 \leq \mathrm{Z} / \mathrm{L} \leq 1.00$. 


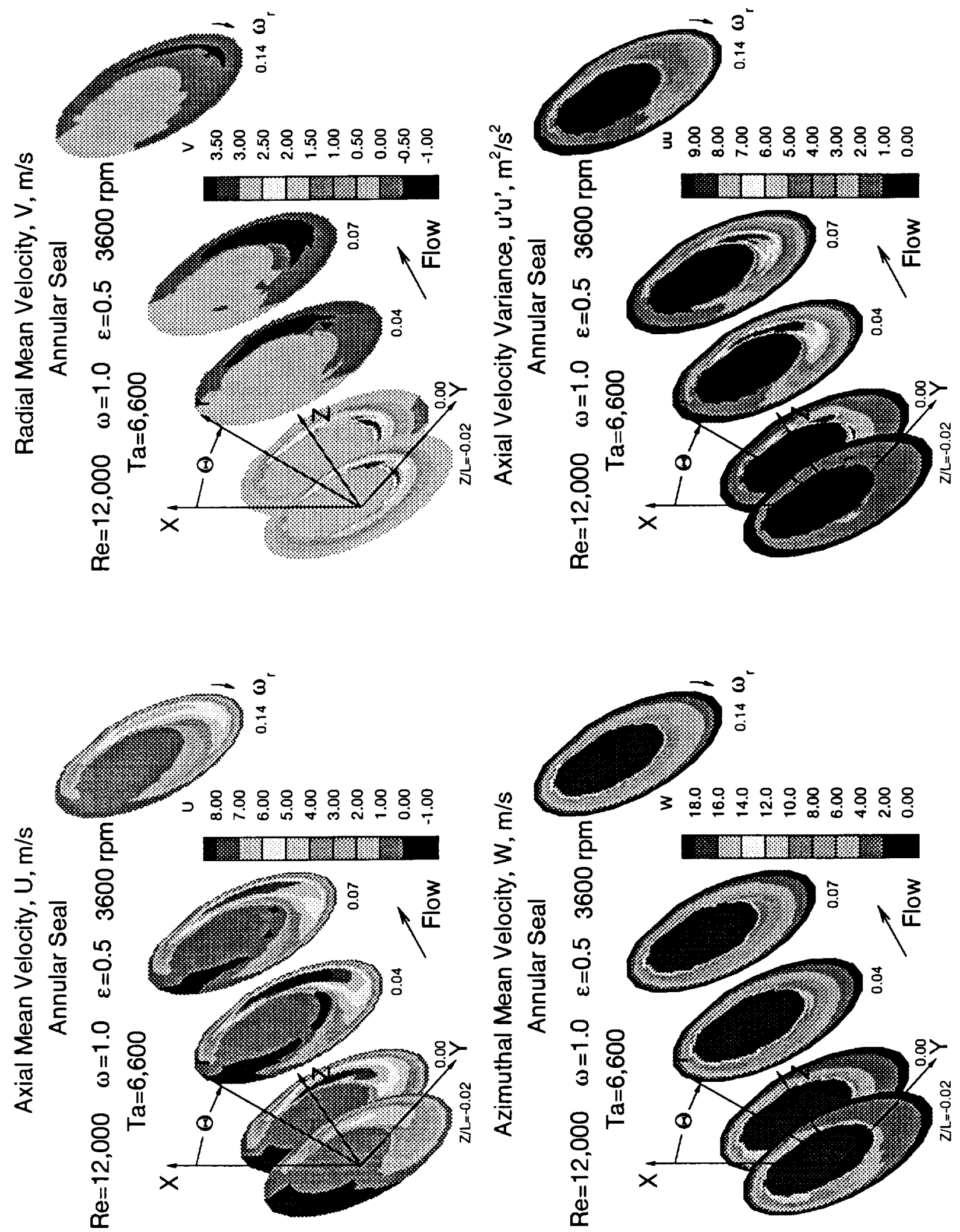

Figure 3. Mean velocity and axial velocity variance, $\operatorname{Re}=12,000,-0.02 \leq \mathrm{Z} / \mathrm{L} \leq 0.14$. 


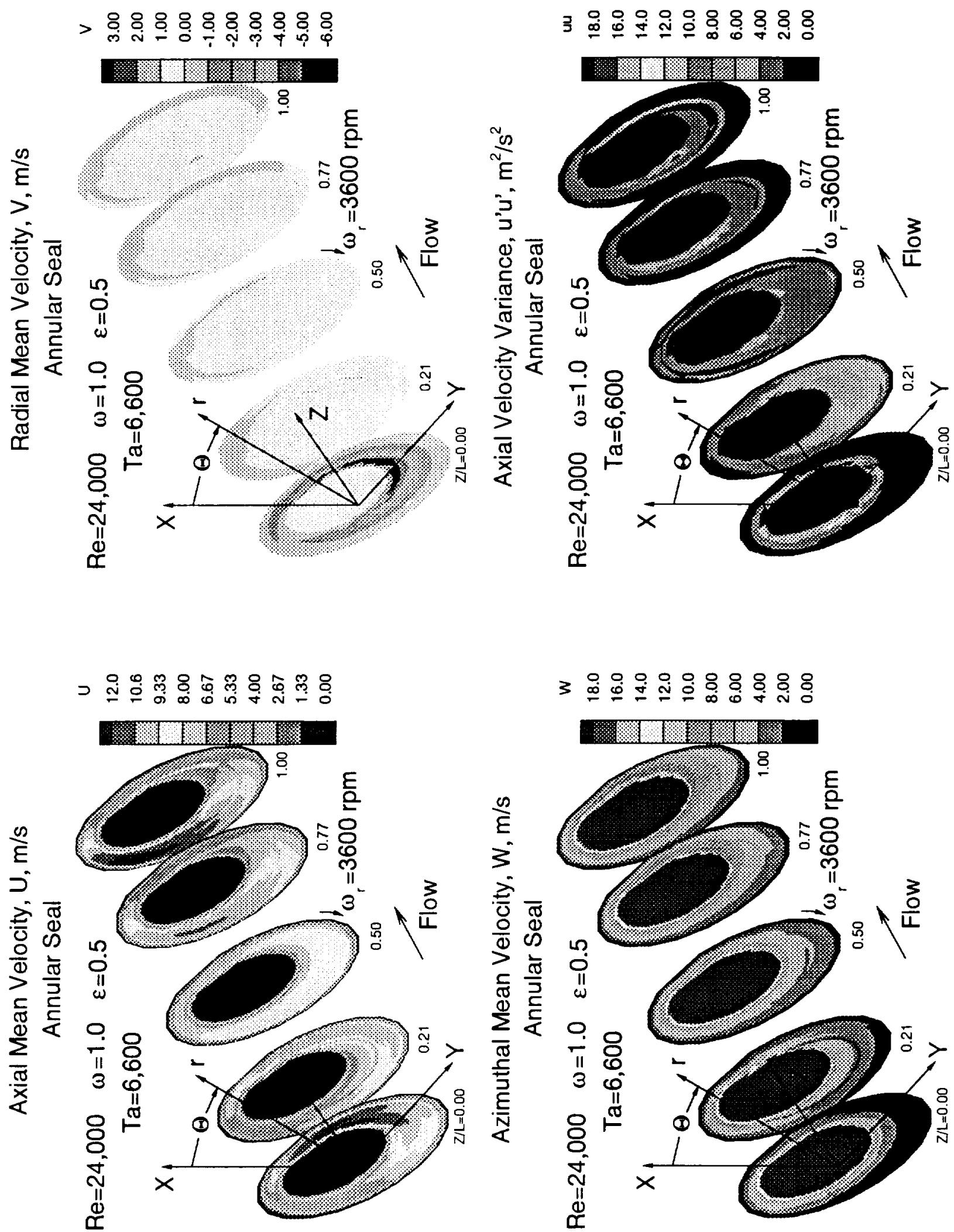

Figure 4. Mean velocity and axial velocity variance, $R e=24,000,0.00 \leq Z / L \leq 1.00$. 



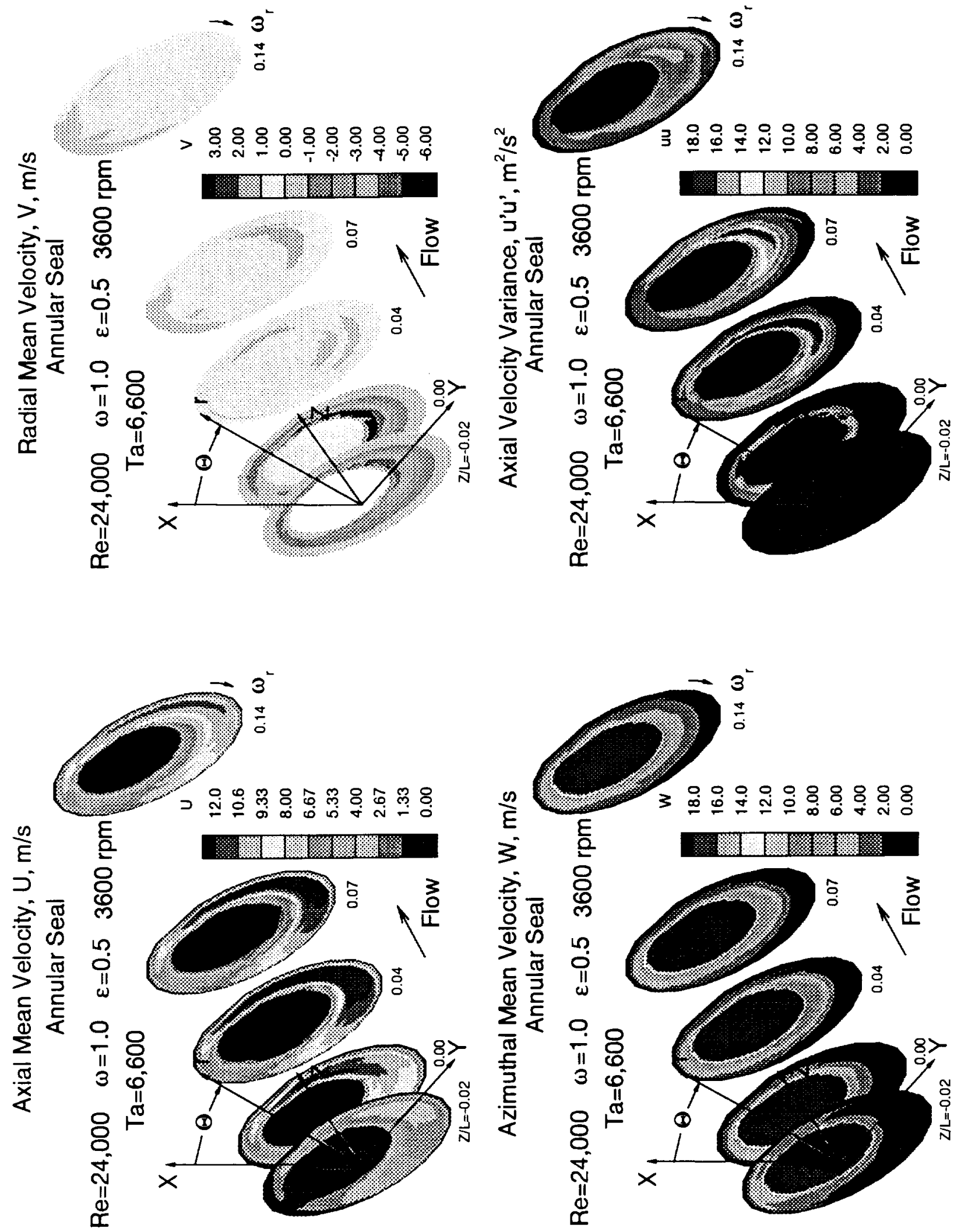

Figure 5. Mean velocity and axial velocity variance, $\mathrm{Re}=24,000,-0.02 \leq \mathrm{Z} / \mathrm{L} \leq 0.14$. 
